\title{
Contra-Thermodynamic Positional Isomerization of Olefins
}

\author{
Kuo Zhao and Robert R. Knowles* \\ Department of Chemistry, Princeton University, Princeton, New Jersey 08544, United States
}

Supporting Information Placeholder

\begin{abstract}
A light-driven method for the contra-thermodynamic positional isomerization of olefins is described. In this work, stepwise PCET activation of a more substituted and more thermodynamically stable olefin substrate is mediated by an excited-state oxidant and a Brønsted base to afford an allylic radical that is captured by a $\mathrm{Cr}$ (II) co-catalyst to furnish an allylchromium(III) intermediate. In situ protodemetalation of this allylchromium complex by methanol is highly regioselective and affords an isomerized and less thermodynamically stable alkene product. The higher oxidation potential of the less substituted olefin isomer renders it inert to further oxidation by the excited-state oxidant, enabling it to accumulate in solution over the course of the reaction. A broad range of isopropylidene substrates is accommodated, including enol ethers, enamides, styrenes, 1,3-dienes, and tetrasubstituted alkyl olefins. Mechanistic investigations of the protodemetalation step are also presented.
\end{abstract}

Synthetic methods for the selective incorporation and manipulation of olefins have been the subject of extensive research efforts. ${ }^{1}$ In this context, positional olefin isomerization is a particularly attractive strategy as it directly interconverts isomeric alkenes through double-bond transposition along a carbon chain. ${ }^{2}$ Leading studies on transition metal-catalyzed olefin isomerization by Cramer, Heck, Wilkinson, Noyori, and others stimulated significant research in this area, resulting in both detailed mechanistic understanding and the development of useful synthetic methods. ${ }^{3}$ More recent advances from Schoenebeck, Shenvi, Holland, Grotjahn, and Mazet have continued to expand the scope of these protocols. ${ }^{4}$ While powerful, thermal olefin isomerizations are limited to accessing equilibrium populations of olefin isomers whose relative concentrations are dictated by their thermodynamic stabilities. As such, thermal catalytic methods can only isomerize less stable alkenes into more stable positions (Figure 1a). To overcome this constraint, numerous two-step methods have been reported wherein an internal olefin is first stoichiometrically converted into a terminal alkyl organometallic intermediate via chain-walking hydrofunctionalization, with subsequent elimination affording a terminal olefin product. ${ }^{5}$ In these protocols, the favorable consumption of a stoichiometric reagent provides the driving force necessary to compensate for the otherwise endergonic isomerization.

Alternatively, photochemical approaches are well-suited to drive reactions against a thermodynamic bias. In addition to the photon absorption event providing an exogenous driving force, the key bond-forming and bond-breaking steps can proceed across multiple potential energy surfaces, providing pathways that bypass the constraints of microscopic reversibility that govern thermal (a) Challenges in contra-thermodynamic positional olefin isomerization

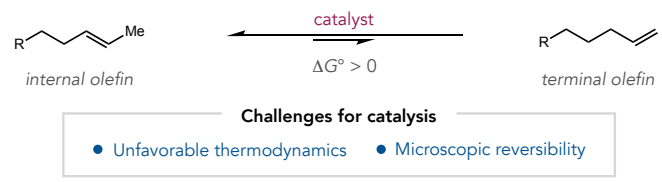

(b) This work: Positional olefin isomerization via dual photoredox \& Cr catalysis

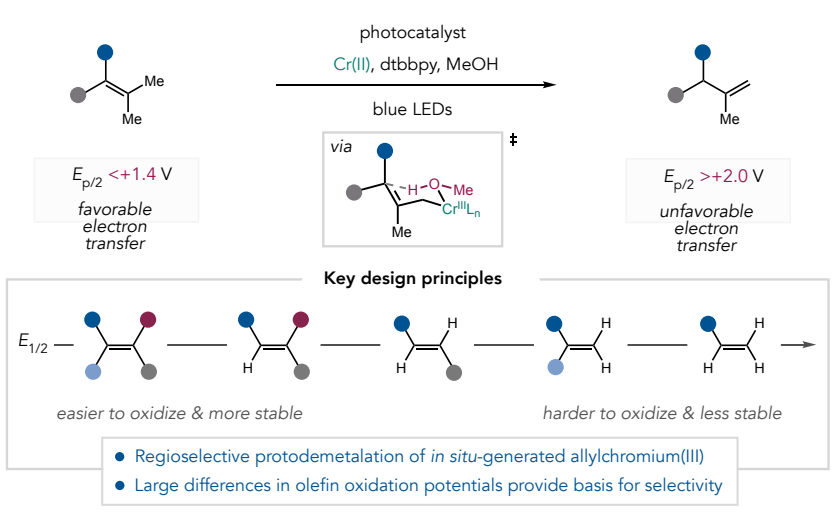

Figure 1. (a) Challenges in developing contra-thermodynamic positional olefin isomerization. (b) This work: light-driven contra-thermodynamic positional olefin isomerization via selective excited-state electron transfer.

processes. ${ }^{6}$ These ideas have been effectively utilized in geometrical olefin isomerization, wherein triplet energy transfer can lead to selective enrichment in the higher energy $Z$-isomers. ${ }^{7}$ Light-driven positional olefin isomerizations have been less extensively studied, though important examples have been reported by Arnold, Pete, Jørgenson, Gilmour, and others. ${ }^{8}$ Seeking to build on these advances, we describe here a light-driven method for the direct contra-thermodynamic isomerization of numerous olefin classes enabled by the selective generation and in situ consumption of a key allylchromium nucleophile (Figure 1b). The design, optimization, and demonstration of this methodology are presented below.

Our approach finds its basis in recent studies from Kanai and Glorius on the photocatalytic allylation of aldehydes with alkenes. ${ }^{9}$ In their work, an electron-rich alkene substrate is first oxidized by an excited-state photocatalyst to form a transient alkene radical cation. The allylic $\mathrm{C}-\mathrm{H}$ bonds in this radical cation are markedly acidified and can be favorably deprotonated by a weak Brønsted base to generate an allylic radical. ${ }^{8 b, 10}$ This stabilized radical intermediate is then captured by a $\mathrm{Cr}$ (II) co-catalyst to furnish an allylchromium(III) complex. In the presence of an aldehyde electrophile, nucleophilic addition occurs via a cyclic transition 
state leading to branched homoallylic alcohol products with high levels of diastereo- and regioselectivity (Figure 2a). ${ }^{11} \mathrm{We}$ questioned whether intercepting the same allylchromium intermediate with an appropriate proton donor would result in similarly regioselective protodemetalation at the more substituted, internal carbon of the allylchromium intermediate, selectively delivering the less substituted olefin isomer. This hypothesis finds support in the independent work of Castro and Kato, wherein allylic chloride electrophiles are treated with excess $\mathrm{Cr}$ (II) salts in the presence of aliphatic alcohols. ${ }^{12}$ Under these conditions, the resulting allylchromium intermediate undergoes in situ protodemetalation via an $\mathrm{S}_{E} 2$ ' process with the alcohol proton donor, producing a terminal olefin product with exceptional regioselectivity (Figure 2b).

(a) Direct allylation of aldehydes with alkenes via dual photoredox and chromium catalysis (Kanai and Glorius)
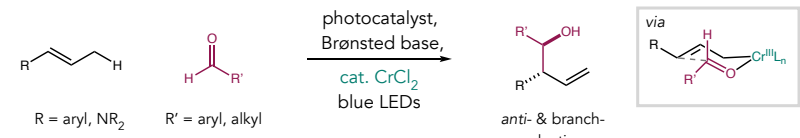

(b) Reduction of allylic chlorides via protodemetalation of allylchromium(III) (Kato)
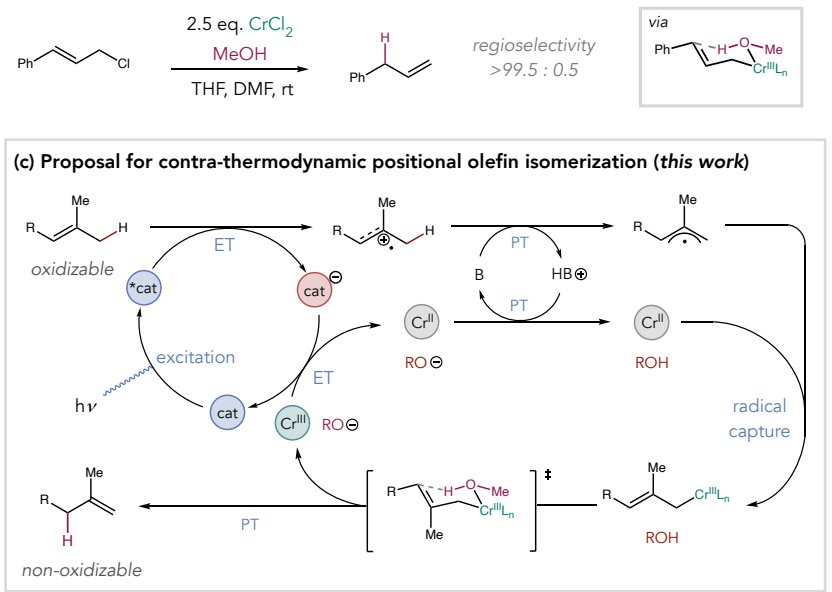

Figure 2. (a) Photoredox and chromium co-catalysis enabled allylation of aldehydes with alkenes. (b) Regioselective protodemetalation of allylchromium intermediates. (c) Prospective catalytic cycle for positional olefin isomerization.

We reasoned that combining these precedents would furnish a catalytic mechanism for contra-thermodynamic positional olefin isomerization jointly mediated by a photoredox catalyst, a Brønsted base, a chromium(II) complex, and an alcohol proton donor. In this scheme, excited-state electron transfer, allylic $\mathrm{C}-\mathrm{H}$ deprotonation, and radical capture by $\mathrm{Cr}(\mathrm{II})$ would form a nascent allylchromium(III) intermediate from the olefin starting material as described above. Subsequent protodemetalation of the allylchromium(III) via an $S_{E} 2$ ' process in the presence of a proton donor would occur regioselectively through a cyclic transition state to furnish the desired less stable olefin product in accord with Kato's findings. The resulting Cr(III) complex can then accept an electron from the reduced state of the photocatalyst while the alkoxide can be protonated by the conjugate acid of the Brønsted base to close the catalytic cycle (Figure 2c). Importantly, we anticipated that the significant differential in oxidation potentials between the more substituted and less substituted alkene isomers would provide a means to maintain selectivity for the contrathermodynamic alkene product. Specifically, an appropriately chosen excited-state oxidant should be able to oxidize the more substituted and thermodynamically stable olefin isomer selectively $\left(E_{p / 2} \sim 1.3 \& \sim 0.7 \mathrm{~V}\right.$ vs $\mathrm{Fc}^{+} / \mathrm{Fc}$ in $\mathrm{MeCN}$ for styrenes and tetrasubstituted alkyl olefins, respectively), while not being thermodynamically competent to engage in electron transfer with the less-substituted isomeric alkene product $\left(E_{p / 2}>2.0 \mathrm{~V} \mathrm{vs} \mathrm{Fc/Fc}\right.$ in $\mathrm{MeCN}$ for 1,1-disubstituted alkenes and terminal alkenes) (Figure 1c). ${ }^{13}$ In this way, the less-substituted (and less thermodynamically stable) olefin isomer should be inert to further reaction and thus be able to accumulate in solution as the reaction progresses.

Table 1. Optimization studies ${ }^{a}$

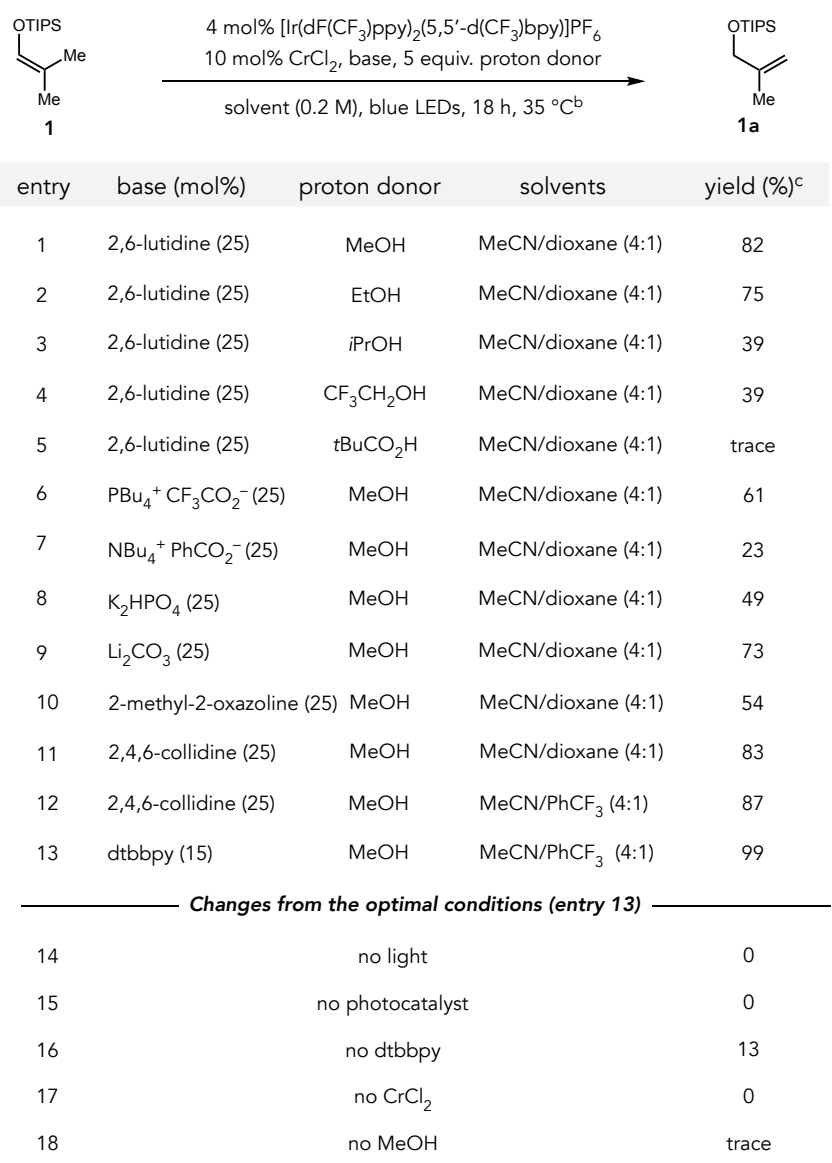

${ }^{a}$ Optimization reactions were performed on $0.05 \mathrm{mmol}$ scale. ${ }^{b}$ Internal temperature of the reaction mixture under 34W LED irradiation $(456 \mathrm{~nm})$ (see SI for details). ${ }^{c}$ Yields were determined by ${ }^{1} \mathrm{H}$ NMR analysis of crude reaction mixtures relative to an internal standard.

We began our investigations using conditions adapted from the aldehyde allylation studies with silyl enol ether $\mathbf{1}$ as a model substrate $\left(E_{p / 2}=+1.26 \mathrm{~V}\right.$ vs $\mathrm{Fc} / \mathrm{Fc}^{+}$in $\left.\mathrm{MeCN}\right)$. We were pleased to find that a combination of $4 \mathrm{~mol} \%$ of $\left[\operatorname{Ir}\left(\mathrm{dF}\left(\mathrm{CF}_{3}\right) \text { ppy }\right)_{2}\left(5,5^{\prime}-\right.\right.$ $\left.\left.\mathrm{d}\left(\mathrm{CF}_{3}\right) \mathrm{bpy}\right)\right] \mathrm{PF}_{6},\left(E_{1 / 2} * \operatorname{Ir}(\mathrm{III}) / \mathrm{Ir}(\mathrm{II})=+1.30 \mathrm{~V} \mathrm{Fc}^{+} / \mathrm{Fc}\right.$ in $\left.\mathrm{MeCN}\right), 10$ $\mathrm{mol} \% \mathrm{CrCl}_{2}, 25 \mathrm{~mol} \%$ 2,6-lutidine, and 5 equivalents of $\mathrm{MeOH}$ under blue light irradiation in a solvent mixture of $\mathrm{MeCN}$ and dioxane $(4: 1 \mathrm{v} / \mathrm{v})$ successfully afforded the isomerized allylic ether 1a in $82 \%$ yield (Table 1, entry 1). ${ }^{9 a}$ A survey of proton donors revealed that primary aliphatic alcohols were particularly effective, with methanol proving optimal (entries 1,2). More sterically demanding secondary alcohols (entry 3 ) and more acidic fluorinated alcohols (entry 4) proved less efficient. The use of carboxylic acids as proton donors was ineffective and resulted in the decomposition of acid-labile 1 (entry 5). Reactions using trifluoroacetate (entry 6), benzoate (entry 7), or inorganic bases (entries 8,9) were effective but afforded 1a in diminished yields. Other heterocyclic bases were also examined (entries 10,11) with 
Table 2. Isomerization of enol ethers and enamides ${ }^{a}$

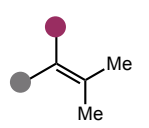

Ir photocatalyst, $10 \mathrm{~mol} \%[\mathrm{Cr}]$ 15 mol\% dtbbpy, 5 equiv. $\mathrm{MeOH}$

solvent (0.2 M), 18 h, blue LEDs
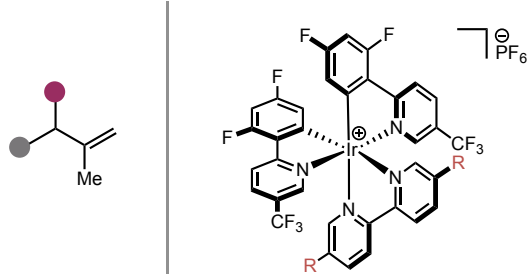

Condition A (enol ethers):

4 mol\% photocatalyst $\left(\mathrm{R}=\mathrm{CF}_{3}\right)$ $[\mathrm{Cr}]=\mathrm{CrCl}_{2}$,

$\mathrm{MeCN} / \mathrm{PhCF}_{3}(4: 1 \mathrm{v} / \mathrm{v}, 0.2 \mathrm{M})$

Condition B (enamides):

2 mol\% photocatalyst $(\mathrm{R}=\mathrm{H})$ $[\mathrm{Cr}]=\mathrm{CrCl}_{3}$, $\mathrm{CH}_{2} \mathrm{Cl}_{2}(0.2 \mathrm{M})$

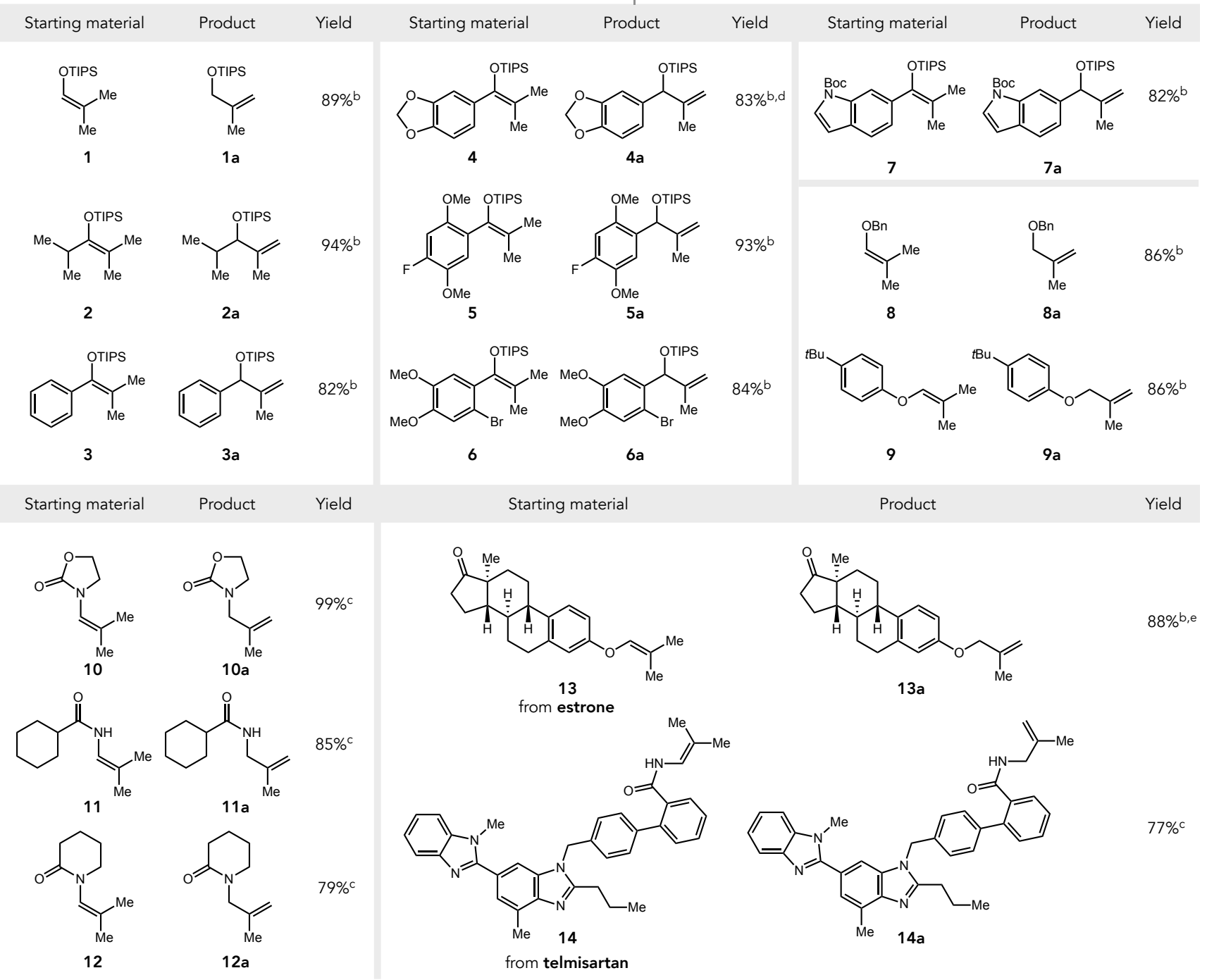

${ }^{a}$ Reactions were run on $0.5 \mathrm{mmol}$ scale. Reported yields are for isolated and purified material and are the average of two experiments. The internal reaction temperature in the reaction setup was measured to be $\sim 40{ }^{\circ} \mathrm{C}$. Details are provided in the Supporting Information. ${ }^{b} \mathrm{Condition}$ A was used. ${ }^{c}$ Condition $\mathbf{B}$ was used. ${ }^{d} 36 \mathrm{~h}$ reaction time. ${ }^{e} 48 \mathrm{~h}$ reaction time.

collidine proving similarly effective to 2,6-lutidine. A further survey of solvents revealed modest improvements in yield when a combination of 4:1 v/v MeCN and trifluorotoluene $\left(\mathrm{PhCF}_{3}\right)$ was employed (entry 12). Lastly, while $\mathrm{CrCl}_{2}$ is poorly soluble in this solvent mixture, we observed solution homogeneity when pyridine bases were employed, suggesting a potential ligation process..$^{14}$ On the basis of these observations, we evaluated common pyridyl ligands for chromium and observed that reactions with $15 \mathrm{~mol} \%$ of 4,4'-di-tert-butyl-2,2'-dipyridyl (dtbbpy) furnished 1a in nearly quantitative yield (entry 13). In these reactions, we hypothesize that the excess dtbbpy ligand may also function as the Brønsted base in the deprotonation of the allylic radical cation. Control experiments indicated that there was no conversion in the absence of photocatalyst or blue light irradiation (entries 14, 15). Similarly, only a low yield of 1a was observed in the absence of the dtbbpy base/ligand (entry 16). The absence of $\mathrm{CrCl}_{2}$ resulted in the complete decomposition of $\mathbf{1}$ (entry 17). In the absence of methanol, only trace product was observed and $\mathbf{1 a}$ was found to undergo partial decomposition (entry 18). Additional details regarding the optimization process are presented in the Supporting Information.

With these optimized conditions in hand, we set out to investigate the generality of this isomerization process for a variety of enol ether substrates (Table 2). On the preparative scale, silyl enol ethers derivatized from aldehydes (1) or ketones (2-7) were amenable to isomerization, including phenyl-substituted $\mathbf{3}$, 
Table 3. Isomerization styrenes, 1,3-dienes, and tetrasubstituted alkenes ${ }^{a}$
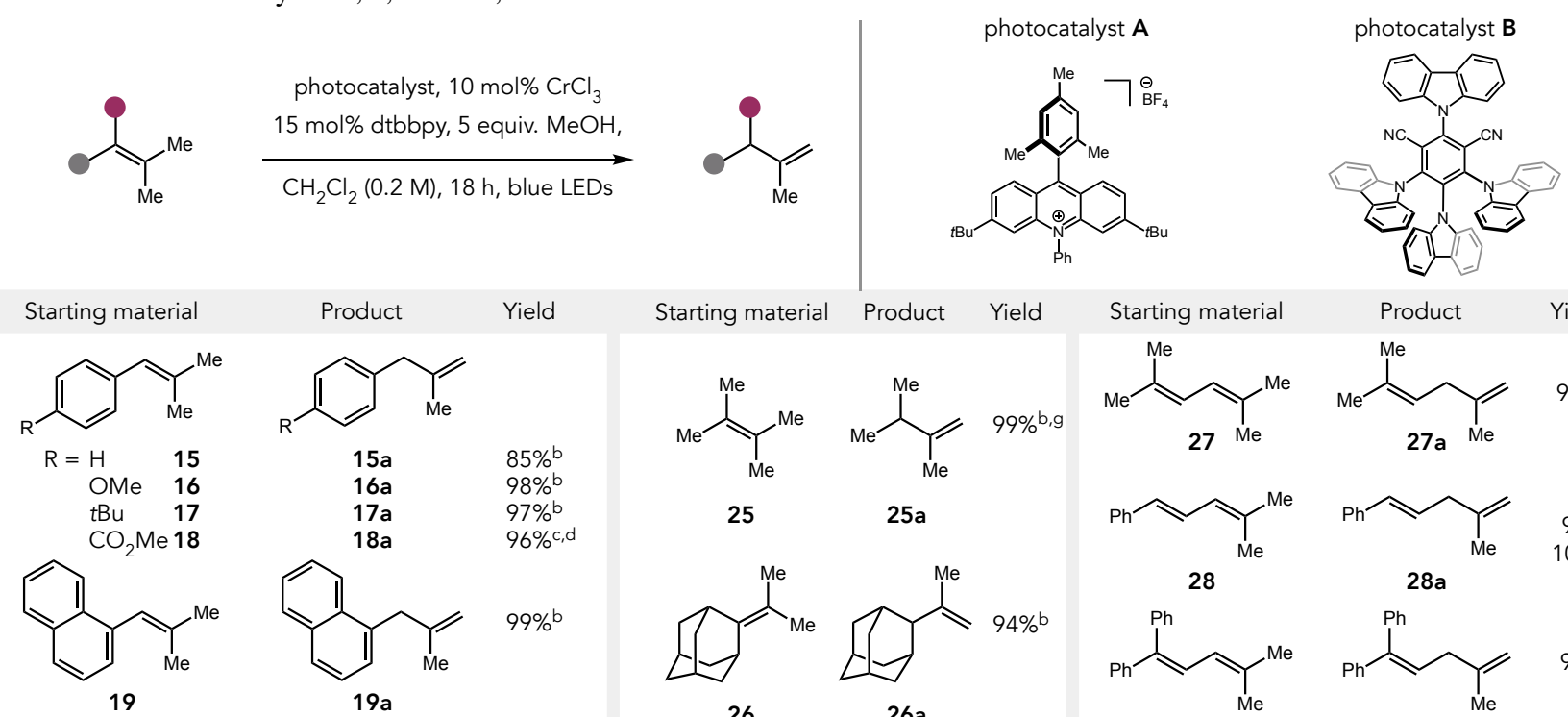<smiles>COc1ccc(/C(C)=C(\C)C(=O)[O-])cc1</smiles><smiles>C=C(O)C(C#N)c1ccc(OC)cc1</smiles><smiles>CC(C)=C(c1ccccc1)c1ccccc1</smiles><smiles>C=C(C(c1ccccc1)c1ccccc1)[N+](=O)[O-]</smiles><smiles>CC(C)=Cc1cnn(-c2ccccc2)c1</smiles>
22<smiles>CC(C)=Cc1cn(C(=O)c2ccccc2)c(C)n1</smiles><smiles>C=C(Cc1cn(C(=O)c2ccccc2)c(CC)n1)Nc1ccccc1</smiles><smiles>CC(C)=Cc1ccc2c(cnn2C(=O)OC(C)(C)C)c1</smiles><smiles>C=C(Cc1ccc2c(cnn2C(=O)OCc2ccccc2)c1)NC(=O)c1ccccc1</smiles>

Starting material

Product

Yield

Starting material<smiles>CC(C)=C(C)[N+](=O)[O-]</smiles><smiles>C=C(O[Na])C(C)C</smiles><smiles>CC(C)=CC=C(C)[N+](=O)[O-]</smiles><smiles>C=C([18O])CC=C(C)C</smiles>

25

$25 a$<smiles>C=C(C)C(C)C1C2CCC(C2)C1C(C)=C(C)C(C)=C1C2CC3CC(C2)CC1C3</smiles>

26

$26 a$<smiles>CC(C)=CC=Cc1ccccc1</smiles>

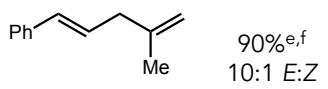
28

$28 a$<smiles>CC(C)=CC=C(c1ccccc1)c1ccccc1</smiles><smiles>C=NC(=C)CC=C(c1ccccc1)c1ccccc1</smiles><smiles>CC(C)=Cc1csc(-c2ccc(C(F)(F)F)cc2)n1</smiles>

30<smiles>C=C(C)Cc1csc(-c2ccc(C(F)(F)F)cc2)n1</smiles>

$89 \%$<smiles>COC(=O)c1sc(-c2ccc(OC)c(C=C(C)[N+](=O)[O-])c2)nc1S(=O)(=O)[O-]</smiles>

31<smiles>COc1ccc(-c2nc(C)c(C(=O)Oc3cc(C=C(C)N)ccc3OC)s2)cc1C#N</smiles>

from febuxostat<smiles>C=C(Cc1cc(-c2nc(C)c(C(=O)OCC)s2)ccc1OC)OC</smiles>

$97 \%$<smiles>C=C(C)Cc1ccc(OC)c(OC(=O)c2sc(-c3ccc(OCCCC)c(C#N)c3)nc2N)c1</smiles>

$86 \%$

${ }^{a}$ Reactions were run on $0.5 \mathrm{mmol}$ scale. Reported yields are for isolated and purified material and are the average of two experiments. The internal reaction temperature in the reaction setup was measured to be $\sim 40{ }^{\circ} \mathrm{C}$. Details are provided in the Supporting Information. ${ }^{b} 1 \mathrm{~mol} \%$ photocatalyst $\mathbf{A}$ was used. ${ }^{c} 3$ mol\% photocatalyst $\mathbf{A}$ was used. ${ }^{d}$ No methanol was added. ${ }^{e} 2$ mol\% photocatalyst $\mathbf{B}$ was used. ${ }^{f}$ Reaction run in $0.2 \mathrm{M} \mathrm{DMF}$ for $36 \mathrm{~h} .{ }^{g} \mathrm{GC}$ yield reported. ${ }^{h} \mathrm{NMR}$ yields reported relative to DMF as an internal standard.

electron-rich aryls (4-6), and indole derivative 7. In addition to enolsilanes, benzyl (8) and aryl enol ethers (9) were also accommodated. We then investigated the isomerization of enamide substrates. Unfortunately, the optimal conditions for the enol ethers were less efficient and resulted in partial decomposition of the substrate and low yields of the desired allylic amine products. Further study revealed that employing the less oxidizing photocatalyst $\left[\operatorname{Ir}\left(\mathrm{dF}\left(\mathrm{CF}_{3}\right) \text { ppy }\right)_{2}(\right.$ bpy $\left.)\right] \mathrm{PF}_{6}\left(E_{1 / 2} * \operatorname{Ir}(\mathrm{III}) / \operatorname{Ir}(\mathrm{II})=+0.94\right.$ $\mathrm{V}$ vs $\mathrm{Fc}^{+} / \mathrm{Fc}$ in $\mathrm{MeCN}$ ) and $\mathrm{CrCl}_{3}$ in dichloromethane solution resulted in improved reaction outcomes (condition B). ${ }^{15}$ Under these modified conditions, we expect that the $\mathrm{CrCl}_{3}$ is reduced in situ by the photocatalyst, enabling numerous enamides to be effectively isomerized, including oxazolidinone 10, secondary amide 11, and lactam 12. Gratifyingly, we found that more complex substrates such as estrone derivative $\mathbf{1 3}$ and telmisartan derivative 14 could also be isomerized in good yields.

We next explored the isomerization of non-heteroatom substituted alkenes, such as styrenes, tetrasubstituted olefins, and 1,3-dienes (Table 3). Due to differences in the redox properties of these alkene classes, we conducted further photocatalyst optimization studies and identified photocatalyst [di-tBu-Mes-Acr] $\mathrm{BF}_{4}$ (A) $\left(E_{1 / 2}\right.$ ${ }^{* 1} \mathrm{Acr}^{+} / \mathrm{Acr} \bullet=+1.72 \mathrm{~V}$ vs $\mathrm{Fc}^{+} / \mathrm{Fc}$ in $\left.\mathrm{MeCN}\right)$ as the most efficient photocatalyst for styrene and tetrasubstituted alkene substrates, while the less oxidizing photocatalyst $4 \mathrm{CzIPN}(\mathbf{B})\left(E_{1 / 2} * \mathrm{PC} / \mathrm{PC}^{*}\right.$ $=+1.05 \mathrm{~V}$ vs $\mathrm{Fc}^{+} / \mathrm{Fc}$ in $\mathrm{MeCN}$ ) proved optimal for 1,3-diene substrates (Table 3). ${ }^{16}$ As in the enamide examples above, the use of $\mathrm{CH}_{2} \mathrm{Cl}_{2}$ and $\mathrm{CrCl}_{3}$ was found to be most efficient for these substrate classes (see Supporting Information for details). With these modified conditions identified, we studied the isomerization of numerous styrenes (15-21) and vinyl heteroarenes $(\mathbf{2 2}-\mathbf{2 4}, \mathbf{3 0}$ 32) on the preparative scale. Electron-rich styrenes, such as $\mathbf{1 6}$ and 17, were well tolerated, providing excellent yields of the deconjugated allyl arene products. Notably, for styrene 18 bearing an electron-withdrawing ester substituent, we observed competitive anti-Markovnikov hydromethoxylation, presumably 
via the addition of methanol to the electrophilic alkene radical cation as documented by Nicewicz and coworkers. ${ }^{17}$ Interestingly, when methanol was omitted from these reactions, the isomerization of 18 still proceeded efficiently, presumably mediated by proton transfer to the allylchromium from the conjugate acid of the dtbbpy base. Tetrasubstituted styrenes $(\mathbf{2 0}, \mathbf{2 1})$ were also found to be efficient substrates. Numerous vinyl heteroarenes, such as pyrazole 22, imidazole 23, and indazole $\mathbf{2 4}$ were also successfully rearranged using catalyst $\mathbf{A}$. In addition, several tetrasubstituted alkyl olefins $(\mathbf{2 5}, \mathbf{2 6})$ could be isomerized into their corresponding 1,1-disubstituted isomers in excellent yields. We were pleased to discover that 1,3-diene substrates (27-29) could undergo selective deconjugation reactions, delivering skipped 1,4-diene products with high selectivity. Similar to the case of $\mathbf{1 8}$, we observed undesired hydromethoxylation in the reactions of $\mathbf{2 8}$ and 29 under the initially optimized conditions. Further experimentation revealed that in the absence of methanol, the reactions of $\mathbf{2 8}$ and 29 proceeded most efficiently in dimethylformamide. Under these modified conditions, 28a was obtained in $90 \%$ yield as a 10:1 mixture of $E: Z$ isomers. Similarly, the isomerization of $\mathbf{2 9}$ produced 29a in an excellent yield of $96 \%$. Lastly, functionalized substrates 30-32 were also effective in the isomerization reaction.

(a) Isotope labeling and kinetic isotope effect experiments

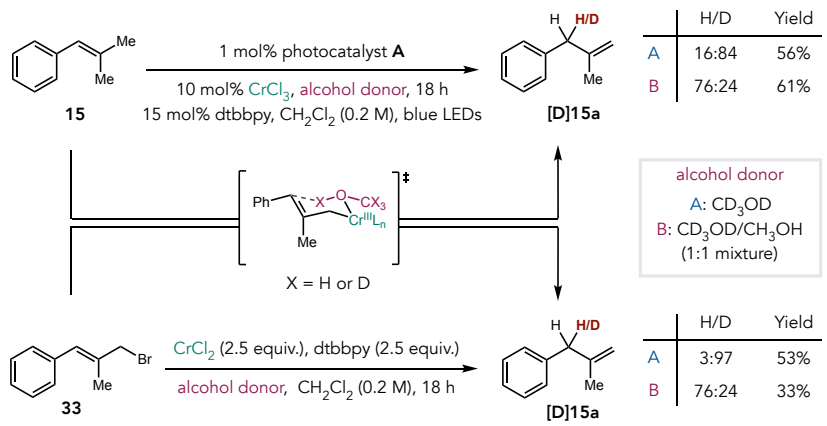

(b) Computational assessment of isomerization thermochemistry

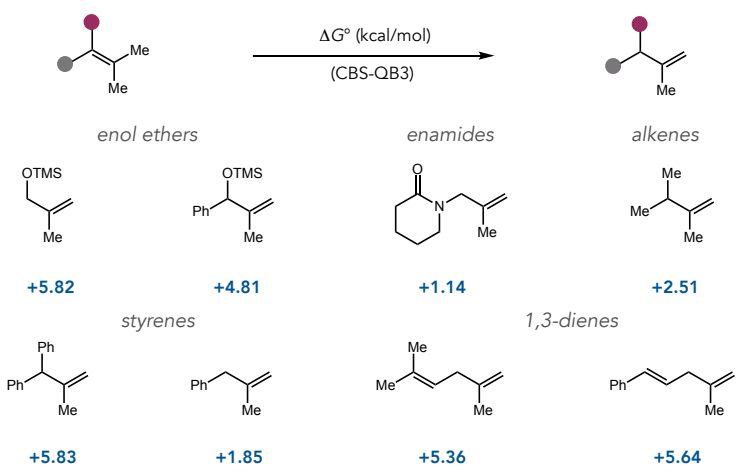

Figure 3. (a) Isotope labeling and competition kinetic isotope effect experiments under catalytic and stoichiometric conditions. (b) Computational assessment of thermochemistry for selected substrates.

To evaluate the proposed mechanism, we conducted a series of isotopic labeling and kinetic isotope effect (KIE) experiments (Figure 3a). We first employed $\mathrm{CD}_{3} \mathrm{OD}$ ( 5 equivalents) in the isomerization of styrene 15 under otherwise standard photocatalytic conditions and observed $84 \%$ deuteration at the newly formed benzylic $\mathrm{C}\left(\mathrm{sp}^{3}\right)-\mathrm{H}$ position of product 15a. Notably, no detectable deuteration was observed at any other position in 15a or in the recovered starting material 15. These observations indicate both that deprotonation of the allylic radical cation is irreversible and that the protodemetalation step is highly regioselective. Next, we studied the stoichiometric reduction of $(E)$-(3-bromo-2-methylprop-1-en-1yl)benzene 33 using excess $\mathrm{CrCl}_{2}$ under conditions similar to those employed in the catalytic protocol but without either the photocatalyst or visible-light irradiation. With $\mathrm{CD}_{3} \mathrm{OD}$, we observed $97 \%$ deuteration exclusively at the newly formed benzylic $\mathrm{C}\left(\mathrm{sp}^{3}\right)-\mathrm{H}$ position of the product 15a. We attribute this modest difference in deuteration efficiency to the in situ generation of $\mathrm{CD}_{3} \mathrm{OH}$ under the photocatalytic conditions via deprotonation of the allylic $\mathrm{C}-\mathrm{H}$ bonds in the alkene radical cation. We next conducted competition kinetic isotope experiments for both the catalytic and the stoichiometric reactions using a mixture of $1: 1 \mathrm{CH}_{3} \mathrm{OH}$ and $\mathrm{CD}_{3} \mathrm{OD}(10$ equivalents each). In both cases, we observed a H/D ratio of 76:24 for incorporation of the hydrogen isotopes at the newly formed benzylic $\mathrm{C}\left(\mathrm{sp}^{3}\right)-\mathrm{H}$ position of $\mathbf{1 5 a}$. The correspondence between the competition KIE values in the photocatalytic and stoichiometric conditions is consistent with selectivity-determining protodemetalation of a common allylchromium(III) intermediate in both reactions. Notably, when parallel reactions are carried out using either $\mathrm{CH}_{3} \mathrm{OH}$ or $\mathrm{CD}_{3} \mathrm{OD}$ under the photocatalytic conditions, the ratio of observed rates $\left(k_{\mathrm{H}} / k_{\mathrm{D}}\right)$ was $\sim 1.2$, indicating that protodemetalation occurs after the rate-limiting step of the catalytic cycle. ${ }^{18}$ Lastly, computational assessment (CBS-QB3) of the isomerization thermochemistry for selected substrates demonstrates the ability of this light-driven protocol to selectively furnish the thermodynamically less stable olefin products (Figure 3b).

In conclusion, we have developed a method for the contrathermodynamic positional isomerization of isopropylidenecontaining olefins utilizing photoredox and chromium co-catalysis. Selectivity in this process occurs through the in situ formation and consumption of a key allyl organometallic intermediate, while the thermodynamics are driven by excited-state electron transfer events. These results further highlight the ability of photoredox catalysis to enable energetically unfavorable reactions of significance in organic synthesis that may be challenging to achieve using conventional thermal catalysts. Efforts to expand the scope and generality of this protocol are ongoing.

\section{ASSOCIATED CONTENT}

\section{Supporting Information}

The Supporting Information is available free of charge on the ACS Publications website.

Experimental details, characterization data, and spectra (PDF). Crystallographic data for 31a (CIF).

\section{AUTHOR INFORMATION}

\section{Corresponding Author}

rknowles@princeton.edu

\section{Notes}

The authors declare no competing financial interests. Crystallographic data are deposited with the Cambridge Crystallographic Data Centre (CCDC) under the following accession numbers: 31a (2104994)

\section{Acknowledgment}

This work was supported as part of BioLEC, an Energy Frontier Research Center funded by the U.S. Department of Energy, Office of Science, Basic Energy Sciences under Award \#DE-SC0019370. The authors thank Suhong Kim for assistance with calculations and Phil Jeffrey for assistance with X-ray crystallography. 


\section{References}

(1) (a) Larsen, C. R.; Grotjahn, D. B. The Value and Application of Transition Metal Catalyzed Alkene Isomerization in Industry. In Applied Homogeneous Catalysis with Organometallic Compounds: A Comprehensive Handbook in Four Vols.; Cornils, B., Herrmann, W. A., Beller, M., Paciello, R., Eds.; Wiley, 2018; pp 1365-1378. (b) Stephen, J. C.; Cutler, H. G.; Biologically Active Natural Products: Pharmaceuticals; CRC Press: Boca Raton, FL, 2000. (c) Mander, L. N. Comprehensive Natural Products II: Chemistry and Biology; Elsevier: Amsterdam, 2010. (d) Allen, G.; Bevington, J. C.; Booth, C.; Price, C. Comprehensive Polymer Science: The Synthesis, Characterization, Reactions \& Applications of Polymers; Pergamon: Oxford, 1989

(2) (a) Fiorito, D.; Scaringi, S.; Mazet, C. Transition Metal-Catalyzed Alkene Isomerization as an Enabling Technology in Tandem, Sequential and Domino Processes. Chem. Soc. Rev. 2021, 50, 1391-1406. (b) Massad, I.; Marek, I. Alkene Isomerization through Allylmetals as a Strategic Tool in Stereoselective Synthesis. ACS Catal. 2020, 10, 5793-5804. (c) Liu, X.-F.; Li, B.; Liu, Q. Base Metal-Catalyzed Olefin Isomerization Reactions. Synthesis 2019, 51, 1293-1310. (d) Molloy, J. J.; Morack, T.; Gilmour, R. Positional and Geometrical Isomerisation of Alkenes: The Pinnacle of Atom Economy. Angew. Chem., Int. Ed. 2019, 58, 13654-13664. (e) Holland, P. L. Distinctive Reaction Pathways at Base Metals in High-Spin Organometallic Catalysts. Acc. Chem. Res. 2015, 48, 1696-1702. (f) Hassam, M.; Taher, A.; Arnott, G. E.; Green, I. R.; van Otterlo, W. A. L. Isomerization of Allylbenzenes. Chem. Rev. 2015, 115, 5462-5569. (g) Larionov, E.; Li, H.; Mazet, C. Well-defined Transition Metal Hydrides in Catalytic Isomerizations. Chem. Commun. 2014, 50, 9816-9826. (h) Donohoe, T. J. O'Riordan, T. J. C.; Rosa, C.P. Ruthenium-Catalyzed Isomerization of Terminal Olefins: Applications to Synthesis. Angew. Chem., Int. Ed. 2009, 48, 1014-1017.

(3) (a) Cramer, R.; Lindsey, Jr., R. V. The Mechanism of Isomerization of Olefins with Transition Metal Catalysts. J. Am. Chem. Soc. 1966, 88 , 3534-3544. (b) Heck, R. F.; Breslow, D. S. The Reaction of Cobalt Hydrotetracarbonyl with Olefins. J. Am. Chem. Soc. 1961, 83, 4023-4027. (c) Davies, N. R. Palladium-catalysed Olefine Isomerization. Nature 1964, 201, 490-491. (d) Harrod, J. F.; Chalk, A. J. Mechanism of Double-bond Migration catalysed by Group VIII Metal Complexes. Nature 1965, 205, 280-281. (e) Yagupsky, M.; Wilkinson, G. Further Studies on Hydridocarbonyltris(triphenylphosphine)rhodium(I). Part II. Isomerisation of $n$-Pentenes and Hex-1-ene. J. Chem. Soc. A, 1970, 941-944. (f) Inoue, S.-I.; Takaya, H.; Tani, K.; Otsuka, S.; Sato, T.; Noyori, R. Mechanism of the Asymmetric Isomerization of Allylamines to Enamines Catalyzed by 2,2'-Bis(diphenylphosphino)-1,1'-binaphthyl Rhodium Complexes. J. Am. Chem. Soc. 1990, 112, 4897-4905.

(4) (a) Paulson, E. R.; Moore, C. E.; Rheingold, A. L.; Pullman, D. P.; Sindewald, R. W.; Cooksy, A. L.; Grotjahn, D. B. Dynamic $\pi$-Bonding of Imidazolyl Substituent in a Formally 16-Electron $\mathrm{Cp} * \mathrm{Ru}\left(\varkappa^{2}-P, N\right)^{+}$Catalyst Allows Dramatic Rate Increases in $(E)$-Selective Monoisomerization of Alkenes. ACS Catal. 2019, 9, 7217-7231. (b) Crossley, S. W. M.; Barabé, F.; Shenvi, R. A. Simple, Chemoselective, Catalytic Olefin Isomerization. J. Am. Chem. Soc. 2014, 136, 16788-16791. (c) Guven, S.; Kundu, G.; Weßels, A.; Ward, J. S.; Rissanen, K.; Schoenebeck, F. Selective Synthesis of Z-Silyl Enol Ethers via Ni-Catalyzed Remote Functionalization of Ketones. J. Am. Chem. Soc. 2021, 143, 8375-8380. (d) Kundu, G.; Sperger, T.; Rissanen, K.; Schoenebeck, F. A Next-Generation Air-Stable Palladium(I) Dimer Enables Olefin Migration and Selective C-C Coupling in Air. Angew. Chem., Int.Ed. 2020, 59, 21930-21934 (e) Kapat, A.; Sperger, T.; Guven, S.; Schoenebeck, F. E-Olefins through Intramolecular Radical Relocation. Science 2019, 363, 391-396. (f) Kim, D.; Pillon, G.; DiPrimio, D. J.; Holland, P. L. Highly Z-selective Double Bond Transposition in Simple Alkenes and Allylarenes through a Spin-accelerated Allyl Mechanism. J. Am. Chem. Soc. 2021, 143, 3070-3074. (g) Chen, C.; Dugan, T. R.; Brennessel, W. W.; Weix, D. J.; Holland, P. L. Z-Selective Alkene Isomerization by High-Spin Cobalt(II) Complexes. J. Am. Chem. Soc. 2014, 136 945-955. (h) Lin, L.; Romano, C.; Mazet, C. Palladium-Catalyzed LongRange Deconjugative Isomerization of Highly Substituted $\alpha, \beta$-Unsaturated Carbonyl Compounds. J. Am. Chem. Soc. 2016, 138, 10344-10350.

(5) (a) Hanna, S.; Wills, T.; Butcher, T. W.; Hartwig, J. F. Palladium-Catalyzed Oxidative Dehydrosilylation for Contra-Thermodynamic Olefin Isomerization. ACS Catal. 2020, 10, 8736-8741. (b) Hanna, S.; Butcher, T. W.; Hartwig, J. F. Contra-thermodynamic Olefin Isomerization by ChainWalking Hydrofunctionalization and Formal Retro-hydrofunctionalization Org. Lett. 2019, 21, 7129-7133. (c) Li, J.; Qu, S.; Zhao, W. Rhodium- catalyzed Remote $\mathrm{C}\left(\mathrm{sp}^{3}\right)$-H Borylation of Silyl Enol Ethers. Angew. Chem. Int. Ed. 2020, 59, 2360-2364.

(6) (a) Shin, N. Y.; Ryss, J. M.; Zhang, X.; Miller, S. J.; Knowles, R. R. Light-Driven Deracemization Enabled by Excited-State Electron Transfer Science 2019, 366, 364-369. (b) Hölzl-Hobmeier, A.; Bauer, A.; Silva, A. V.; Huber, S. M.; Bannwarth, C.; Bach, T. Catalytic Deracemization of Chiral Allenes by Sensitized Excitation with Visible Light. Nature 2018, 564 , 240-243. (c) Musacchio, A. J.; Lainhart, B. C.; Zhang, X.; Naguib, S. G.; Sherwood, T.C.; Knowles, R. R. Catalytic Intermolecular Hydroaminations of Unactivated Olefins with Secondary Alkyl Amines. Science, 2017, 355, 727-730. (d) Ota, E.; Wang, H.; Frye, N. L.; R.; Knowles, R. R. A Redox Strategy for Light-Driven, Out-of-Equilibrium Isomerizations and Application to Catalytic C-C Bond Cleavage Reactions. J. Am. Chem. Soc. 2019 141, 1457-1462. (e) Depolymerization of Hydroxylated Polymers via Light-Driven C-C Bond Cleavage. Nguyen, S. T.; McLoughlin, E.; Cox, J. H.; Fors, B. P.; Knowles, R. R. J. Am. Chem. Soc. 2021, 143, 12268-12277. (f) Wang, Y.; Carder, H. M.; Wendlandt, A. E. Synthesis of Rare Sugar Isomers through Site-Selective Epimerization. Nature 2020, 578, 403-408. (g) Dalton, D. M.; Ellis, S. R.; Nichols, E. M.; Mathies, R. A.; Toste, F. D.; Bergman, R. G.; Raymond, K. G. Supramolecular $\mathrm{Ga}_{4} \mathrm{~L}_{6}{ }^{12-}$ Cage Photosensitizes 1,3-Rearrangement of Encapsulated Guest via Photoinduced Electron Transfer. J. Am. Chem. Soc. 2015 137, 10128-1013. (h) Kathan, M. Hecht, S. Photoswitchable Molecules as Key Ingredients to Drive Systems Away from the Global Thermodynamic Minimum. Chem. Soc. Rev. 2017, 46, 5536-5550. (i) Astumian, R. D. Optical vs. Chemical Driving for Molecular Machines. Faraday Discuss. 2016, 195, 583-597.

(7) (a) Hammond, G. S.; Saltiel, J. Photosensitized Cis-Trans Isomerization of the Stilbenes. J. Am. Chem. Soc. 1962, 84, 4983-4984. (b) Arai, T.; Sakuragi, H.; Tokumaru, K. Unusual Behaviour of $\beta$-tert-Alkylstyrenes in Photosensitized Cis-Trans Isomerization. Structural Effects on Triplet Energy Transfer. Chem. Lett. 1980, 9, 261-264. (c) Arai, T.; Sakuragi, H.; Tokumaru, K. Photosensitized cis-trans Isomerization of $\beta$-Alkylstyrenes Bull. Chem. Soc. Jpn. 1982, 55, 2204-2207. (d) Molloy, J. J.; Schäfer, M.; Wienhold, M.; Morack, T.; Daniliuc, C. G.; Gilmour, R. Boron-Enabled Geometric Isomerization of Alkenes via Selective Energy-Transfer Catalysis. Science 2020, 369, 302-306. (e) Metternich, J. B.; Gilmour, R. A. BioInspired, Catalytic $E \rightarrow Z$ Isomerization of Activated Olefins. J. Am.Chem. Soc. 2015, 137, 11254-11257. (f) Singh, K.; Staig, S. J.; Weaver, J. D. Facile Synthesis of Z-Alkenes via Uphill Catalysis. J. Am. Chem. Soc. 2014, 136, 5275-5278. (g) Metternich, J. B.; Gilmour, R. Photocatalytic $E \rightarrow Z$ Isomerization of Alkenes. Synlett 2016, 27, 2541-2552. (h) Neveselý, T.; Wienhold, M.; Molloy, J. J.; Gilmour, R. Advances in the $E \rightarrow Z$ Isomerization of Alkenes Using Small Molecule Photocatalysts. Chem. Rev. 2021, DOI: $10.1021 /$ acs.chemrev.1c00324.

(8) (a) Morack, T.; Onneken, C.; Nakakohara, H.; Mück-Lichtenfeld, C.; Gilmour, R. ACS Catal. 2021, 11, 11929-11937. (b) Mangion, D.; Kendall, J.; Arnold, D. R. Photosensitized (Electron Transfer) Deconjugation of 1Arylcyclohexenes. Org. Lett. 2001, 3, 45-48. (c) Pete, J.-P.; Hénin, F.; Mortezaei, R.; Muzart, J.; Piva, O. Enantioselective Photodeconjugation of Conjugated Esters and Lactones. Pure Appl. Chem. 1986, 58, 1257-1262. (d) Yang, N. C.; Jorgenson, M. J. Photochemical Isomerization of Simple $\alpha, \beta-$ Unsaturated Ketones. Tetrahedron Lett. 1964, 5, 1203-1207. (e) Ho, T.-I.; Li, T.-C. New Deconjugation Reaction of $(E)$-1-Indanylidene Methylarene Brought by Photolysis with Protic acid. Tetrahedron Lett. 2004, 45, 5665-5667. (f) Wan, Y.; Kurchan, A.; Kutateladze, A. Photoinduced 1,3Proton Shift in Methyldithiepines as a Potential Way of Modulating Hyperpolarizabilities. J. Org. Chem. 2001, 66, 1894-1899. (g) Duguid, R. J. Morrison, H. Photochemistry of 3-Methyl- and 4-Methyl-1,2-dihydronaphthalene in Solution. J. Am. Chem. Soc. 1991, 113, 1265-1271.

(9) (a) Schäfers, F.; Quach, L.; Schwarz, J. L.; Saladrigas, M.; Daniliuc, C. G.; Glorius, F. Direct Access to Monoprotected Homoallylic 1,2-Diols via Dual Chromium/Photoredox Catalysis. ACS Catal. 2020, 10, 11841-11847. (b) Schwarz, J. L.; Schäfers, F.; Tlahuext-Aca, A.; Lückemeier, L.; Glorius, F. Diastereoselective Allylation of Aldehydes by Dual Photoredox and Chromium Catalysis. J. Am. Chem. Soc. 2018, 140, 12705-12709. (c) Tanabe, S.; Mitsunuma, H.; Kanai, M. Catalytic Allylation of Aldehydes Using Unactivated Alkenes. J. Am. Chem. Soc. 2020, 142, 12374-12381. (d) Mitsunuma, H.; Tanabe, S.; Fuse, H.; Ohkubo, K.; Kanai, M. Catalytic Asymmetric Allylation of Aldehydes with Alkenes Through Allylic C $\left(\mathrm{sp}^{3}\right)$ -H Functionalization Mediated by Organophotoredox and Chiral Chromium Hybrid Catalysis. Chem. Sci. 2019, 10, 3459-3465.

(10) (a)Schmittel, M.; Burghart, A. Understanding Reactivity Patterns of Radical Cations. Angew. Chem., Int. Ed. 1997, 36, 2550-2589. (b) Albini, A.; Mella, M.; Freccero, M. A New Method in Radical Chemistry: 
Generation of Radicals by Photo-induced Electron Transfer and Fragmentation of the Radical Cation. Tetrahedron 1994, 50, 575-607.

(11) Fürstner, A. Carbon-Carbon Bond Formations Involving Organochromium(III) Reagents. Chem. Rev. 1999, 99, 991-1046.

(12) (a) Omoto, M.; Kato, N.; Sogon, T.; Mori, A. Revisit to the reduction of allylic chlorides to less substituted olefins by a low-valent chromium species in the presence of a proton source. Tetrahedron Lett. 2001,42,939941. (b) Castro, C. E.; Kray, Jr., W. C. The Cleavage of Bonds by Low Valent Transition Metal Ions. The Homogeneous Reduction of Alkyl Halides by Chromous Sulfate. J. Am. Chem. Soc. 1963, 85, 2768-2773.

(13) Roth, H. G.; Romero; N. A.; Nicewicz, D. A. Experimental and Calculated Electrochemical Potentials of Common Organic Molecules for Applications to Single-Electron Redox Chemistry. Synlett, 2016, 27, 714-723.

(14) Stamos, D. P.; Sheng, X. C.; Chen, S. S.; Kishi, Y. Ni(II)/Cr(II)-Mediated Coupling Reaction: Beneficial Effects of 4-tert-Butylpyridine as an Additive and Development of New and Improved Workup Procedure. Tetrahedron Lett. 1997, 38, 6355-6358.

(15) Koike, T.; Akita, M. Visible-light Radical Reaction Designed by Ruand Ir-based Photoredox Catalysis. Inorg. Chem. Front. 2014, 1, 562-576. (16) (a) White, A. R.; Wang, L.; Nicewicz, D. A. Synthesis and Characterization of Acridinium Dyes for Photoredox Catalysis. Synlett 2019, 30 , 827-832. (b) Shang, T.-Y.; Lu, L.-H.; Cao, Z.; Liu, Y.; He, W.-M.; Yu, B. Recent Advances of 1,2,3,5-Tetrakis(carbazol-9-yl)-4,6-dicyanobenzene (4CzIPN) in Photocatalytic Transformations. Chem. Commun. 2019, 55, 5408-5419.

(17) (a) Hamilton, D. S.; Nicewicz, D. A. Direct Catalytic Anti-Markovnikov Hydroetherification of Alkenols. J. Am. Chem. Soc. 2012, 134 18577-18580. (b) Margrey, K. A.; Nicewicz, D. A. A General Approach to Catalytic Alkene Anti-Markovnikov Hydrofunctionalization Reactions via Acridinium Photoredox Catalysis. Acc. Chem. Res. 2016, 49, 1997-2006.

(18) Simmons, E. M.; Hartwig, J. F. On the Interpretation of Deuterium Kinetic Isotope Effects in $\mathrm{C}-\mathrm{H}$ Bond Functionalizations by TransitionMetal Complexes. Angew. Chem., Int. Ed. 2012, 51, 3066-3072. 


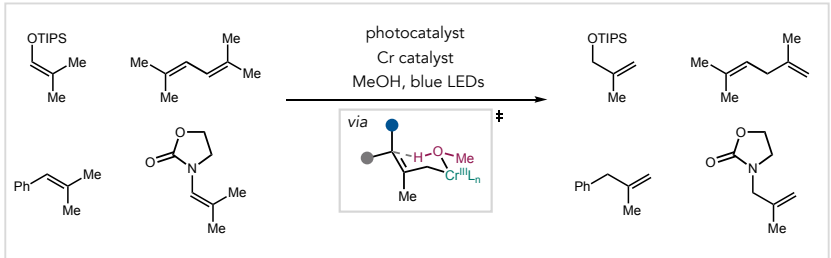

Light-driven contra-thermodynamic positional isomerization of olefins 